\title{
PROVÁVEL MODELO DE ORIGEM E EVOLUÇÃO DOS HORIZONTES FERRUGINOSOS DA BACIA DE SÃO PAULO COM BASE NA GEOQUÍMICA DE SUPERFÍCIE
}

\author{
J.B.Sígolo ${ }^{1}$ \& C.S.Ohnuma ${ }^{2}$
}

PALAVRAS-CHAVE: Crostas ferruginosas, geoquímica, evolução, distribuição, mineralogia, Bacia de São Paulo.

SíGOLO, J.B.; OHNUMA, C.S. (1996) Provável modelo de origem e evolução dos horizontes ferruginosos da Bacia de São Paulo com base na geoquimica de superficie. Bol.IG-USP, Sér.Cient., 27:137-149.

\section{RESUMO}

Este trabalho versa sobre a evoluçăo geoquimica, descriçăo mineralógica e micromorfológica, e a distribuiçăo geográfica das crostas ferruginosas encontradas em sedimentos da Bacia de São Paulo.

Dois tipos de crostas foram identificados: um superficial mais antigo e outro subsuperficial mais recente. Este segundo tipo ocorre nas áreas estudadas em pelo menos três horizontes que se encaixam nos sedimentos da Bacia de São Paulo, ou ainda ocorrem como preenchimento de antigas fraturas existentes nestes mesmos sedimentos.

Ambos tipos foram originados através de flutuaçðes do lençol freático, propiciando a precipitação de hidróxidos de ferro no interface de sedimento poroso e permeável superposto com sedimento impermeável sotoposto.

As crostas ferruginosas encontradas e estudadas na área apresentam-se em três camadas nos sedimentos da bacia que, da base para o topo, săo as seguintes:

1. A primeira situada a cerca de $20 \mathrm{~m}$ da superficie, superposta à camada argilosa ocre e sotoposta à camada de silte arenoso,

2. A segunda, a pouco mais de $5 \mathrm{~m}$ da superficie, superposta a camada de argila e sotoposta à camada arenosa.

3. A terceira, aflorante em superficie, e superposta à camada argilosa ocre.

Os diagramas geoquímicos discriminativos destas três camadas, exibem distinção entre elas. A mais marcante é quanto ao conteúdo de ferro e aluminio nestas camadas. A de superficie distingue-se das outras duas por apresentar maior enriquecimento em óxido de ferro e maior empobrecimento em óxido de alumínio. A descrição micromorfológica mostrou que a camada superior exibe granulometria mais grossa que as duas camadas inferiores e que a camada superior não guarda textura reliquiar, enquanto que as duas camadas inferiores guardam textura reliquiar do sedimento do qual se originam.

\footnotetext{
'Departamento de Geologia Geral, Instituto de Geociências/USP, Săo Paulo, Brasil.
}

${ }^{2}$ Aluna de Iniciaçăo Científica, IG/USP. 


\section{ABSTRACT}

This paper presents the mineralogical, micromorphological and geochemical evolution and as well as geographic distribution of iron crusts in the São Paulo Basin. Two types of crusts were identified, an older one near the surface and a younger type in the subsurface within underlying sediments.

Both derive from the underlying sediments through variations in the water table which propitiated iron hydroxides precipitation at the contact between a porous, permeable sediment above, and impermeable sediments below.

The ferricrusts are found in at least three levels within the sediments of the basin, which are from the bottom to the top: 1) about $20 \mathrm{~m}$ below the surface with ochre-colored clay covered by sandy silt; 2) $5 \mathrm{~m}$ below the surface with purplish clay overlain by sand and, finally, 3) the surface crust where it characteristic features of ferricrust are evident. Geochemical diagrams show that the uppermost crust is enriched in $\mathrm{Fe}_{2} \mathrm{O}_{3}$ and poorer in $\mathrm{Al}_{2} \mathrm{O}_{3}$ than the other two layers crusts.

Micromorphological analysis shows that the surficial ferricrust are marked by larger grain size than in the deeper crusts, which show relic textural features of the original sediments. This feature is not found in the surface ferricrust.

\section{INTRODUÇÃO}

A primeira descrição mais detalhada sobre as crostas ferruginosas endurecidas da Bacia de São Paulo foi apresentada por Suguio \& Barbour (1969), que abordaram principalmente a morfologia geral destas crostas. Pela sua resistência mecânica, estas crostas representam hoje obstáculos importantes na execução de obras civis na grande São Paulo. No âmbito da geotecnia, elas estabelecem condições geológicas adversas à implantação de diferentes tipos de obras. Por exemplo, na construção do Metrô de São Paulo foram encontradas inúmeras dificuldades no trecho da Avenida Paulista onde ocorrem concentrações destas crostas. A distribuição destas, conjugada com a distribuição dos sedimentos da Bacia Terciária de São Paulo, permite determinar que estas crostas são freqüentes (Fig. 1).

As informaçōes sobre a morfologia, a origem e a evolução destas crostas ferruginosas associadas aos sedimentos da Bacia de São Paulo fornecem subsídios úteis à Engenharia Civil, à Geotecnia e à Mecânica de Solos (Suguio et al., 1971), já que essas atividades introduzem modificações no meio físico por ação antrópico-tecnológica e, em conseqưência, acabam atingindo estes horizontes na sua área de atuação.

Além de representarem um obstáculo à construção civil, as camadas ferruginosas endurecidas funcionam como importante estrutura de sustentação fisica da configuração geomorfológica (Ab'Saber, 1990; Suguio et al., 1979) do espigão da Avenida Paulista, do Alto do Jaguaré e das imediações do Municipio de Osasco (Parque Continental).

\section{MATERIAIS E MÉTODOS}

Neste trabalho foram usados dois métodos principais de investigação: o primeiro envolveu técnicas convencionais de observação de campo aplicadas em geologia e o segundo constou de estudos geoquímicos aplicados a produtos de alteração dos sedimentos, acompanhados de análise micromorfológica do material. No segundo caso empregou-se descrição macroscópica de fragmentos endurecidos e de crostas ferruginosas em lupa binocular, acompanhada da caracterização mineralógica, granulométrica e química dos diferentes materiais. 


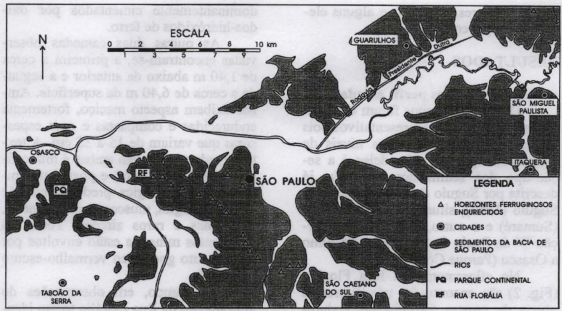

Figura 1 - Distribuição parcial dos horizontes ferruginosos endurecidos na Bacia Sedimentar de São Paulo. Base: Carta Geológica da região metropolitana de Grande Săo Paulo (Emplasa, 1980). Escala: 1:100.000.

Os trabalhos de campo foram fundamentados em descrições prévias sobre os sedimentos da bacia principalmente os trabalhos de Carvalho \& Leinz (1957) e Suguio \& Barbour (1969). A análise geomorfológica da bacia fundamentou-se nos trabalhos de Almeida $(1958,1964)$, Coppedê (1988) e de Ab' Saber (1957, 1969, 1990).

Vários afloramentos descritos nestes trabalhos foram objeto de investigação. O resultado foi a coleta de inúmeras amostras das crostas ferruginosas endurecidas encontradas em diferentes afloramentos. Estas foram submetidas a tratamento específico para estudo (impregnação, determinação de densidade aparente, análise química, etc).

A disposição espacial das camadas endurecidas foi estabelecida com base nestes trabalhos e nas relações de relevo com os horizontes. Com estes dados foi possivel compreender o comportamento espacial e a distribuição destes materiais nos locais estudados que foram confrontados com o arcabouço es- trutural definido por falhas, fraturas etc, superimpostas à bacia (Almeida et al., 1984; Riccomini et al., 1987; Coutinho, 1989). Parte importante destas informações foi obtida em relatórios de empresas de sondagens executadas para as obras do Metrô de São Paulo (MetrôMSP, 1990). A localização dos pontos amostrados e estudados das camadas ferruginosas endurecidas encontram-se na Figura 1.

A amostragem das camadas ferruginosas endurecidas compreendeu tanto a porção dura como os sedimentos imediatamente sotopostos e superpostos à camada. Este procedimento visou a verificação das prováveis similaridades texturais, mineralógicas e micromorfológicas entre estes materiais amostrados. Todos os materiais coletados foram submetidos à análise macroscópica por lupa binocular, microscópica e, algumas amostras foram submetidas à difração de raios X (DRX).

As análises químicas dos materiais compreenderam a detecção dos ele- 
mentos maiores, menores, e alguns elementos traços como o $\mathrm{Ti}$.

\section{RESULTADOS}

\section{Características dos perfis estudados}

Dois afloramentos foram considerados como os mais representativos pois exibiam com clareza vários níveis de crostas ferruginosas. Um deles é a seção-tipo dos sedimentos da bacia, já descrita por Suguio \& Barbour (1969) e Suguio (1980), situada na Rua Florália (Sumaré) e o outro, localizado na porção W da Bacia de São Paulo, próximo a Osasco (Parque Continental).

No afloramento da Rua Florália (Fig. 2) são encontrados três diferentes níveis de crostas ferruginosas endurecidas. A primeira, na superficie do terreno, apresenta textura microconglomerática, e sua espessura não ultrapassa os $50 \mathrm{~cm}$. Apresenta-se intensamente fragmentada e possui composição heterogênea, dando-lhe caráter polimítico. Encontra-se no local fortemente afetada pela ocupação urbana (fragmentação e deslocamento das crostas ferruginosas e outras formações superficiais, aterros recobrindo diferentes afloramentos, etc). Constitui-se majoritariamente de gräos e seixos de quartzo, eventualmente de quartzito e argila parcialmente arredondados, os quais encontram-se pre-

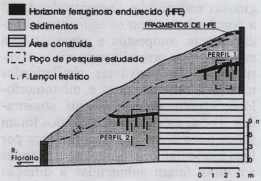

Figura 2 - Perfis esquemáticos do afloramento da Rua Florália. dominantemente cimentados por óxidos-hidróxidos de ferro.

As outras duas camadas observadas encontram-se, a primeira a cerca de $1,40 \mathrm{~m}$ abaixo da anterior e a segunda a cerca de $6,40 \mathrm{~m}$ da superfície. Ambas exibem aspecto maciço, fortemente endurecidas e compactas e com espessuras que variam de 15 a $35 \mathrm{~cm}$. A textura predominante em ambas é muito fina (menos que $2 \mathrm{~mm}$ ) e possuem composição mineralógica predominante de quartzo e argila, muscovita (em pontos), turmalinas e raros zircões. Todos os fragmentos minerais estão envoltos por um cimento goethítico vermelho-escuro amarelado.

No campo, em observações do afloramento da Rua Florália foram identificadas duas camadas ferruginosas endurecidas passando gradativamente, quando observados da base para o topo, a sedimentos siltico-argilosos de coloração variegada.

No afloramento do Parque Continental (Fig. 3), foram reconhecidas e descritas quatro camadas ferruginosas endurecidas. A superior é similar à descrita na Rua Florália, exceto pela sua espessura maior, que neste caso atinge cerca de $1,30 \mathrm{~m}$. Sua textura é microconglomerática, com inclusão de fragmentos de argila ocre e com grânulos de quartzo e pequenas placas de muscovita. Estes fragmentos minerais encontram-se cimentados por goethita. A camada em questão está assentada diretamente sobre um horizonte arenoso microconglomerático, no qual ocorrem fragmentos centimétricos a decimétricos de argila ocre endurecida.

Os horizontes endurecidos inferiores assemelham-se também aos dois descritos na Rua Florália, exibindo textura muito fina, com placas de muscovita sempre envoltas em cimento também fino e compacto de óxidos e hidróxidos de ferro. 

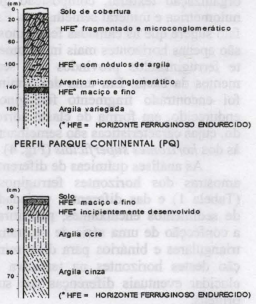

PERFIL 1

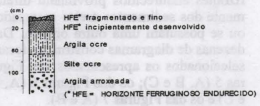

PERFIL 2

Figura 3 - Perfil esquemático do afloramento do Parque Continental.

\section{Composição textural e mineral das camadas ferruginosas}

As camadas ferruginosas endurecidas observadas na Bacia de São Paulo podem ser classificadas em dois grupos distintos, o primeiro representado pela camada superficial e o segundo representado pelas camadas encontradas abaixo e no interior dos sedimentos da bacia. Para efeito de simplificação, a descrição e caracterização destes dois grupos será empregada aqui a designação de horizontes superficiais, para as camadas que afloram na superficie e de horizontes subsuperficiais para as que se encontram no interior dos sedimentos da bacia.
Em geral estes dois grupos são semelhantes do ponto de vista de sua composição mineral, predominando quartzo, com caulinita e muscovita, cimentados por goethita, além de hematita, magnetita e compostos amorfos de ferro. Não foi possivel detectar se a hematita e a magnetita são de origem autigênica ou clástica.

As principais diferenças observadas nestes dois grupos de horizontes ficam por conta da composição química, além de diferenças na textura, cor, tipo de fraturamento e na granulometria do material.

Nos horizontes superficiais, 0 exame macroscópico permitiu identificar grãos de quartzo de $2 \mathrm{~mm}$ a $3 \mathrm{~cm}$, subangulosos, por vezes bastante fraturados, maciços e de aspecto hialino. $\mathrm{O}$ correm em associação com estes grãos de quartzo, nódulos centimétricos a decimétricos de argila fina de cor ocre. Os diferentes grãos, nódulos e fragmentos encontram-se cimentados predominantemente por goethita.

Ao microscópio, os horizontes superficiais apresentam cerca de $40 \%$ de quartzo hialino, bem preservados ou parcialmente corroídos (menos de $10 \%$ ). Associam-se placas submilimétricas de muscovita (próximas de 0,1 $\mathrm{mm}$ ), caulinita em forma de acordeão e pequenos fragmentos argilosos de cor ocre, parcial ou totalmente envolvidos por um plasma ferruginoso de óxidos e hidróxidos de ferro perfazendo de 50 a $60 \%$ da composição total da amostra. Estes óxidos e hidróxidos de ferro encontram-se também preenchendo fissuras e microfraturas do material (Fig. 4).

Os horizontes subsuperficiais apresentam coloração castanho escura avermelhada, aspecto maciço e a composição mineral exibe granulometria fina e semelhante aos horizontes superficiais. O quartzo é o mineral predominante, além da muscovita, hematita, magnetita e goethita, esta última corres- 


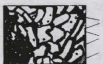

Quartos comoido

Plasma femuginoso (oxido de Fe) Muscovita if af $14.421 \mathrm{~mm}$

Hortzonte feruginoso endurecido microconglomera tico

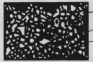

Quartoo

Muscovita

Plasna feruginoso

$$
\text { i. } 0.7 .4 .42 .1 \mathrm{~mm}
$$

Hbrizonte feruginoso endurecido fino e maciço

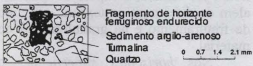

Sedimento com fragmento de horizonte ferug inoso endurecido

Figura 4 - Esquema micromorfológico dos dois tipos distintos de horizontes ferruginosos endurecidos e do sedimento com fragmento (clasto) de horizonte ferruginoso endurecido.

pondendo a mais de $50 \%$ da amostra.

Aspecto interessante a destacar é que as camadas dos sedimentos da bacia situadas logo acima ou logo abaixo destes horizontes, apresentam também organização textural, composição granulométrica e mineral semelhantes. Este fato sugere que as camadas ferruginosas são apenas horizontes mais intensamente ferruginizados provindos dos sedimentos da bacia. Em uma das lâminas foi encontrado fragmento ferruginoso endurecido, em forma de clasto corroido, cujas características são semelhantes às dos horizontes superficiais (Fig. 4)

As análises químicas de diferentes amostras dos horizontes ferruginosos (Tabela 1) e das diferentes variedades de sedimentos encaixantes, permitiram a confecção de uma série de diagramas triangulares e binários para discriminação destes horizontes na tentativa de elucidar eventuais diferenças nas suas origens.

Pretendia-se estabelecer se os horizontes endurecidos provinham diretamente dos sedimentos a eles associados ou se possuiam uma outra origem. Das dezenas de diagramas construídos foram selecionados os apresentados nas Figuras 5 (A, B e C); os das Figuras 6 (A, B e C) e os das Figuras 7 (A e B).

É possivel constatar que o hori-

Tabela 1 - Análises químicas realizadas em diferentes amostras.

\begin{tabular}{|c|c|c|c|c|c|c|c|c|c|c|c|c|c|c|}
\hline - campo & $\mathrm{SiO}_{2}$ & $\mathrm{Al}_{2} \mathrm{O}_{3}$ & $\mathrm{Fe}_{2} \mathrm{O}_{3}$ & $\mathrm{FeO}$ & $\mathrm{CaO}$ & $\mathrm{MgO}$ & $\mathrm{Na}_{2} \mathrm{O}$ & $\mathrm{K}_{2} \mathrm{O}$ & $\mathrm{P}_{2} \mathrm{O}_{5}$ & $\mathrm{TiO}_{2}$ & $\mathrm{MnO}$ & $\mathrm{H}_{2} \mathrm{O}^{+}$ & $\mathrm{H}_{2} \mathrm{O}^{*}$ & \\
\hline PQI-2 & 32,18 & 10,33 & 46,99 & 0,15 &, 03 & 0,05 & 0,05 & 0,31 & 3,15 & 0,35 & 0,05 & 9,15 & 0,9 & inf. \\
\hline$-2 a$ & 2,61 & 10,47 & 42,95 &, 39 &, 05 & 0,1 & 0,1 & 0,38 & 2,9 & 0,28 & 0,05 & 8,92 & 0,8 & inf. \\
\hline QI-3 & 71,5 & 9,24 & 9,91 &, 29 &, 04 & 0,05 & 0,04 & 0,25 & 2,51 & 0,56 & 0,04 & 4,11 & 1,05 & rgil. \\
\hline $\mathrm{OI}-$ & 1,65 & 8,95 & 9,32 & 72 & .03 & 0,1 & 0,08 & 1,09 & 2,05 &, 29 & 15 & 4,25 & 1,11 & ren. \\
\hline-2 & 8,34 & 13,12 & 9,85 & 0,79 &, 02 &, 11 & 0,09 & 1,07 & 2,23 &, 89 & 11 & 3,86 & 1,01 & ren. \\
\hline RF2a & 71 & 1,65 & 38 & 0,02 & .05 & 08 & 5 & 1,45 & 2,62 & .55 &, 09 & 4,1 & 1,24 & \\
\hline$F Q$ & 3,12 & 15,32 & 23,65 & 0,04 &, 12 & 0,05 & 17 & 1,25 & 2,46 & 67 & 0,05 & 5,87 & 1,15 & \\
\hline & 51 & 13,42 & 22,34 & 0,44 &, 05 & 0,5 & 1 & 0,17 & 2,83 & 0,64 & 0,07 & 6,89 & 1,18 & rgil. \\
\hline FQ-1 & 4,48 & 10,43 & 34,48 & 0,42 & 0,03 &, 13 & 0,12 & 0,89 & 2,89 & 0,57 & 0,05 & 7,11 & 1,34 & inf. \\
\hline $\mathrm{FQ}$ & 45,42 & 9,35 & 32,47 & 0,25 & 0,09 & 0,11 & 0,04 & 0,15 & 2,48 & 0,46 & 0,08 & 7,07 & 0,46 & inf. \\
\hline QC- & 59,56 & 3,08 & 29,9 & 0,22 & 0,09 & 0,16 & 0,05 & 0,11 & 2,32 & 0,19 & 0,05 & 3,12 & 0,49 & uper. \\
\hline QC-4 & 61,82 & 2,88 & 28,03 & 0,38 & 0,1 & 0,1 & 0,09 & 0,68 & 2,67 & 0,15 & 0,09 & 3,57 & 0,58 & uper. \\
\hline $5 x=2$ & 22,53 & 8,34 & 58,05 & 0,41 & 0,08 &, 11 & 3 & 0,72 & 87 & 34 & 0,07 & 5,98 & 1,17 & \\
\hline FP-1 & 25,52 & 6,75 & 55,41 & 0,29 & 0,06 & 0,03 & 0,15 & 1,23 & 2,72 & 0,38 & 0,11 & 6,47 & 1,48 & \\
\hline RFP-2-B & 42,71 & 14,08 & 32,45 & 0,23 & 0,05 & 0,89 & 0,08 & 1,13 & 2,97 & 0,59 & 0,13 & 7,45 & 1,4 & \\
\hline RFP-1-a & 43,85 & 12,67 & 29,8 & 0,32 & 0,03 & 0,1 & 0,11 & 1,16 & 2,45 & 0,57 & 0,14 & 7,25 & 1,33 & cour.inf. \\
\hline
\end{tabular}



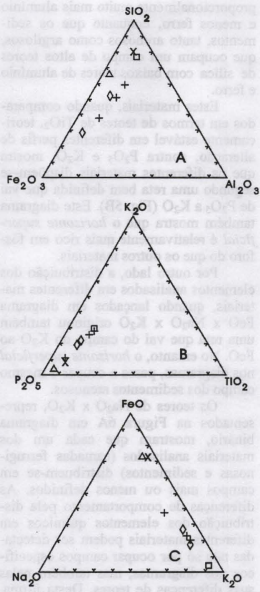

LEGENDA

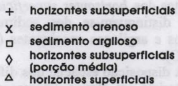

Figuras 5 A, B, C - Diagramas geoquímicos triangulares do conteúdo de $\mathrm{SiO}_{2} \times \mathrm{Al}_{2} \mathrm{O}_{3} \times \mathrm{Fe}_{2} \mathrm{O}_{3}$ (A), $\mathrm{K}_{2} \mathrm{OxP}_{2} \mathrm{O}_{5} \times \mathrm{TiO}_{2}$ (B), $\mathrm{FeOxNa} \mathrm{OxK}_{2} \mathrm{O}$ (C), para as médias das análises quimicas dos horizontes ferruginosos subsuperficiais, superficiais e sedimentos argiloso e arenoso.

\section{LEGENDA}
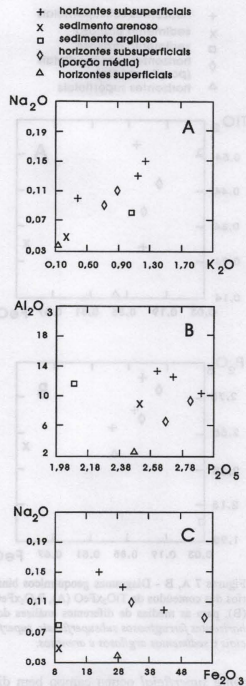

Figuras 6 A, B, C - Diagramas geoquímicos binários dos conteúdos de $\mathrm{Na}_{2} \mathrm{OxK}_{2} \mathrm{O}(\mathrm{A}), \mathrm{Al}_{2} \mathrm{O}_{3}$ $x_{2} \mathrm{O}_{5}(\mathrm{~B})$, e de $\mathrm{Na}_{2} \mathrm{OxFe}_{2} \mathrm{O}_{3}$ (C), para as médias de diferentes análises dos horizontes ferruginosos subsuperficiais, superficlais e sedimentos argilosos $e$ arenosos. 


\section{LEGENDA}
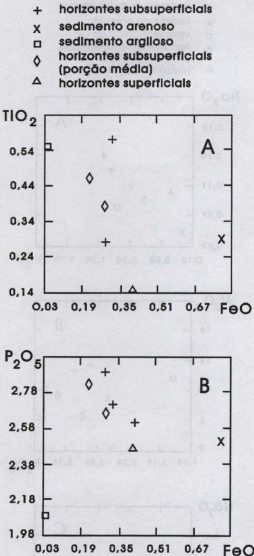

Figuras 7 A, B - Diagramas geoquimicos binários dos conteúdos de $\mathrm{TiO}_{2} \times \mathrm{FeO}(\mathrm{A}), \mathrm{P}_{2} \mathrm{O}_{3} \times \mathrm{FeO}$ (B), para as médias de diferentes análises dos horizontes ferruginosos subsuperficiais, superficiais e sedimentos argilosos e arenosos.

zonte superficial ocupa campo bem diferenciado nos diagramas. Verifica-se na Figura 5A uma menor concentração de alumínio que nos demais materiais analisados, que também parecem ocupar campos bem delineados no diagrama. As camadas ferruginosas apresentam proporcionalmente muito mais alumínio e menos ferro, enquanto que os sedimentos, tanto arenosos como argilosos, que ocupam um campo de altos teores de sílica com baixos teores de alumínio e ferro.

Estes materiais, quando comparados em termos de teores de $\mathrm{TiO}_{2}$, teoricamente estável em diferentes perfis de alteração, contra $\mathrm{P}_{2} \mathrm{O}_{5}$ e $\mathrm{K}_{2} \mathrm{O}$, mostra que os diferentes materiais dispõem-se segundo uma reta bem definida que vai de $\mathrm{P}_{2} \mathrm{O}_{5}$ a $\mathrm{K}_{2} \mathrm{O}$ (Fig. 5B). Este diagrama também mostra que o horizonte superficial é relativamente mais rico em fósforo do que os outros materiais.

Por outro lado, a distribuição dos elementos analisados em diferentes materiais, quando lançados em diagrama $\mathrm{FeO} \times \mathrm{Na}_{2} \mathrm{O} \times \mathrm{K}_{2} \mathrm{O}$ originou também uma reta que vai do campo do $\mathrm{K}_{2} \mathrm{O}$ ao FeO. No entanto, o horizonte superficial nos diagramas, passa a ocupar o mesmo campo dos sedimentos arenosos.

Os teores de $\mathrm{Na}_{2} \mathrm{O} \times \mathrm{K}_{2} \mathrm{O}$, representados na Figura $6 \mathrm{~A}$ em diagrama binário, mostram que cada um dos materiais analisados (camadas ferruginosas e sedimentos) distribuem-se em campos mais ou menos definidos. As diferenças de comportamento pela distribuição dos elementos químicos em diferentes materiais podem ser detectadas não só por ocupar campos específicos nos diagramas, mas também pelas suas diferenças de teores. Desta forma, os horizontes subsuperficiais são bem diferentes dos horizontes superficiais, e ambos distinguem-se dos sedimentos arenosos e argilosos encaixantes (Figs. $6 \mathrm{~A} \mathrm{e} 6 \mathrm{C})$.

A disposição espacial dos diferentes materiais em alguns diagramas, sugere que os horizontes ferruginosos superficiais e subsuperficiais foram originados pela concentração de cimento ferruginoso nos sedimentos argilosos e arenosos (Figs. 5A, B e C; 6A).

A disposição dos pontos nos dia- 
gramas permite discriminar campos específicos para cada tipo de material. Os horizontes subsuperficiais formam um campo bem delimitado, diferente dos demais materiais. As amostras plotadas no mesmo diagrama e que correspondem aos horizontes superficiais, embora um tanto quanto dispersas, também permitem delimitar um campo específico, caracterizado por conteúdo menor em alumínio e maior em ferro.

Por sua vez, as amostras de sedimentos, ocupam posições nos diferentes diagramas, permitindo separá-las dos horizontes ferruginosos. Caracterizamse pelos teores muito maiores em alumínio e menores em ferro, se comparados aos horizontes ferruginosos, tanto superficiais como subsuperficiais.

\section{DISCUSSÃO}

Os resultados das análises texturais, minerais e químicas dos horizontes ferruginosos superficiais e subsuperficiais, bem como dos sedimentos encaixantes, permitem apresentar as seguintes considerações:

1. Nos horizontes subsuperficiais encontram-se presentes feições e texturas reliquiares bastante semelhantes às dos sedimentos superpostos ou sotopostos a eles, sugerindo que essas camadas ferruginosas tenham sido originadas a partir da cimentação por óxidos e hidróxidos de ferro daqueles sedimentos.

2. A maioria dos diagramas geoquimicos envolvendo horizontes superficiais, subsuperficiais e os sedimentos da bacia, também indicam haver uma origem a partir dos sedimentos na formação dos horizontes subsuperficiais.

3. Embora de não muito fácil comprovação, parece haver uma comtínua evolução desses materiais a partir dos sedimentos da bacia, pelo seu gradual empobrecimento em $\mathrm{Al}_{2} \mathrm{O}_{3}$, acompanhado de concomitante enriqueci- mento em $\mathrm{Fe}_{2} \mathrm{O}_{3}$. Não obstante serem os teores levemente mais altos em ferro nos horizontes superficiais que nos subsuperficiais, a característica marcante que distingue estes dois horizontes é dada pelos teores de aluminio bem superiores nos subsuperficiais que nos superficiais.

4. Esses fatos parecem confirmar a origem de ambos horizontes ferruginosos a partir dos sedimentos, porém a perda acentuada de alumínio e a concentração elevada de ferro, quando em ausência de textura reliquiar sedimentar, não permite descartar outro mecanismo genético.

5. A análise das considerações acima permitem estimar que a geração destes dois grupos de horizontes ferruginosos ocorreu sob condições climáticas distintas. Sendo esta afirmação verdadeira, pode-se considerar que estes horizontes foram gerados em períodos cronológicos diferentes.

Alguns pontos acerca da formação da Bacia de São Paulo, principalmente relativos à configuração geomorfológica e estrutural, encontram-se relativamente elucidados a partir de diferentes trabalhos (Ab'Saber, 1957, 1969, 1990). Coppedê (1988) demonstra que a chamada Superficie do Alto Tietê foi inicialmente erodida por volta do Mioceno médio, a partir do desnivelamento e basculamento de blocos no interior da bacia. $\mathrm{O}$ clima neste período, segundo o autor, seria do tipo semi árido. $\mathrm{Na}$ sequêência desta história evolutiva, novo ciclo tectônico tomou conta da área e, neste palco, foram imprimidas discretas acelerações e reorientações no desenvolvimento do entalhamento erosivo na Bacia de São Paulo. Tais eventos devem ter ocorrido por volta do Pliopleistoceno (Coppedê, 1988). Menção sobre estes eventos e sua posição cronológica na evolução da bacia são encontrados em Coppedê (1988) e em Takiya (1991).

A análise destes aspectos acima 
permitem propor a provável formação e evolução dos horizontes ferruginosos de superficie e de subsuperfice aqui descritos. O clima proposto por Coppedê (1988) é propício à formação de coberturas ferruginosas endurecidas. Pode residir neste ponto, o início de formação dos horizontes ferruginosos endurecidos superficiais definidos neste trabalho.

A existência de diferentes ciclos erosivos, atuando sobre os horizontes endurecidos formados em um primeiro estágio (provavelmente no Pliopleistoceno), não só os destruiu em parte, como transformou-os em clastos que foram participar dos sedimentos da bacia. Este aspecto esclarece a existência de clastos com características de horizontes ferruginosos encontrados nos sedimentos pelos autores deste trabalho.

A combinação destes argumentos permite propor que as formas de relevo presentes hoje na área estudada representem o produto da atuação de processos erosivos simultâneos ou não com movimentos tectônicos ascensionais moderados, os quais permitiram os desnivelamentos e basculamentos de blocos no interior da bacia, favorecendo assim distintos ciclos erosivos mencionados em diferentes trabalhos que versam sobre a formação da Bacia de São Paulo.

A preservação atual das porções mais elevadas, na bacia, resultariam da resistência à erosão oferecida pelos horizontes ferruginosos endurecidos já instalados em pretérito relevo, estabelecendo controle erosivo que se sucedeu neste ambiente.

Há claras alusões de que a instalação da Bacia de São Paulo ocorreu devido ao soerguimento de terrenos do embasamento, os quais delimitaram o fluxo da rede de drenagem desta época. Foi criada assim uma nova estrutura de relevo a qual foi submetida a posteriores soerguimentos até a configuração final da bacia como um todo.

Dentro deste raciocínio ter-se-ia uma rede de drenagem mais antiga que deu lugar à formação de uma nova rede de drenagem representada hoje pelo conjunto Tietê/Pinheiros. Estes soerguimentos consecutivos permitiram modificações importantes no nível de base original do lençol freático, alterando-o no passado e deslocando-o para porções inferiores nos dias atuais. Este deslocamento permitiu a formação de novos horizontes ferruginosos endurecidos (compreendendo os horizontes subsuperficiais aqui descritos).

Estes horizontes ferruginosos endurecidos teriam sido então gerados a partir da alternância de fases climáticas mais áridas para mais úmidas, acompanhadas de soerguimento que conduziu - lençol freático a níveis mais profundos em relação aos sedimentos da bacia. Este rebaixamento do lençol promoveu a dissolução de minerais contendo ferro, associados principalmente a sedimentos argilosos-ferruginosos. Com a deferruginização destes níveis o ferro solubilizado deslocou-se e precipitou-se em zonas específicas, onde a armadilha de fixação era dada por uma camada superior de sedimentos permeável e porosa (horizontes areno argilosos), em contato com uma inferior impermeável (horizontes argilosos).

A Figura 8 exibe um modelo geológico tentativo de explicação da evolução destes horizontes dentro de uma cronologia comparada com as propostas existentes na literatura que versam sobre a evolução da Bacia de São Paulo.

Deste modo, pode-se afirmar que os horizontes ferruginosos superficiais sejam mais antigos do que os subsuperficiais e estes por sua vez, mais novos quanto mais profundos em relação à superficie, sempre respeitando a disposição horizontal destes. Pois, há horizontes ferruginosos endurecidos, inclinados ou acompanhando planos de fraturas ou falhas, os quais não se enquadram neste raciocinio evolutivo. As- 


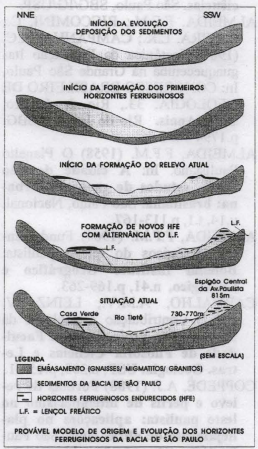

Figura 8 - Provável modelo de evolução para os horizontes ferruginosos endurecidos mostrando a possivel influência das posições do lençol freático na formação dos horizontes ferruginosos.

sim, a história cronológica dos horizontes ferruginosos não se coaduna com o contexto clássico da sobreposição de sedimentos e são, neste caso, contrários a cronologia da sedimentação. Ou seja, quanto mais no topo da seqüência, mais antigos.

\section{CONCLUSÕES}

A análise dos resultados obtidos pela micromorfologia, pela determinação química e interpretação de diferentes diagramas geoquímicos dos horizontes ferruginosos endurecidos da Bacia de São Paulo, permitem as seguintes conclusões:

1. Os horizontes ferruginosos endurecidos da Bacia de São Paulo, podem ser agrupados em dois conjuntos:

a. O primeiro denominado de horizonte superficial, caracterizado pela coloração amarelo ocre, localmente friável e com textura microconglomerática, exibindo grãos de quartzo parcialmente corroídos e associados a nódulos de argila e muscovita em pequenas placas, e

b. O segundo, denominado de horizonte subsuperficial, com coloração castanho-avermelhada e aspecto maciço, de granulação fina e sempre situado entre sedimento superposto poroso e permeável e sedimento sotoposto impermeável.

2. Em geral, as composições minerais dos dois grupos de horizontes ferruginosos são bastante semelhantes. Ambos apresentam grãos de quartzo hialinos mais corroidos no horizonte superficial que nos horizontes de subsuperficie. Estes grãos corroídos provém da dissolução de sílica promovida pela degradação química deste nível, em que a concentração de $\mathrm{Fe}_{2} \mathrm{O}_{3}$ é o ponto principal (ferralitização).

3. Os horizontes subsuperficiais apresentam similaridade com as camadas sobrepostas ou sotopostas de sedimentos quanto às suas características texturais, mineralógicas, granulométricas e composição química.

4. Os horizontes de superficie são mais enriquecidos em $\mathrm{Fe}_{2} \mathrm{O}_{3}$ e empobrecidos em $\mathrm{Al}_{2} \mathrm{O}_{3}$ que os horizontes subsuperficiais, que exibem teores similares tanto de $\mathrm{Fe}_{2} \mathrm{O}_{3}$ como de $\mathrm{Al}_{2} \mathrm{O}_{3}$ quando comparados aos sedimentos a eles associados.

5. Duas ocorrências mais importantes, em termos de concentração atual de horizontes ferruginosos, estão no Espigão da Paulista, e nas elevações opostas a ele na direção SW, próximo à divisa de São Paulo com Osasco. Áreas de ocorrência menos importante estão 
em Colônia (Santo André) e em Itaquaquecetuba.

6. A origem dos horizontes subsuperficiais tem relação com a lixiviação química dos sedimentos sotopostos em que a remobilização de hidróxidos de ferro (deferruginização do horizonte), alumínio e sílica é o mecanismo principal. Neste processo são formados minerais secundários como goethita, óxidos hidróxidos amorfos de ferro, caolinita e quartzo secundário, amplamente disseminados nestes horizontes.

7. As causas da geração de diferentes níveis de horizontes ferruginosos podem ser creditadas a oscilações climáticas, com consequientes flutuaçōes do lençol freático, além das atividades neotectônicas pós-deposicionais.

8. Aparentemente, os horizontes superficiais são mais antigos que os subsuperficiais que, por sua vez, tornam-se cada vez mais novos com o aumento das profundidades da ocorrência.

\section{AGRADECIMENTOS}

Os autores agradecem à FAPESP pelo auxílio-pesquisa (Proc. 90/0033-2) bem como pelo apoio de Iniciação Científica (proc. 90/0032-6) à estudante Cláudia S. Ohnuma.

\section{REFERÊNCIAS BIBLIOGRÁFICAS}

AB'SABER, A.N. (1957) Geomorfologia do sítio urbano de São Paulo. Boletim da Faculdade de Filosofia Ciências e Letras. Geografia. USP, n.219, p.1-335.

AB'SABER, A.N. (1969) Ocorrência de "linhas de pedra" na região de São Paulo. Geomorfologia, n.10, p.9-10. AB'SABER, A.N. (1990) Geomorfologia da região metropolitana de São Paulo. In: SÃO PAULO: O GEÓLOGO E A CIDADE, 1990. Texto e Palestra proferidos na tarde geo- ciências. São Paulo, SBG/IG/USP.

ALMEIDA, F.F.M.; RICCOMINI, C.; DEHIRA, L.K.; CAMPANHA, A.C. (1984) Tectônica da Formação Itaguaquecetuba na Grande São Paulo, In: CONGRESSO BRASILEIRO DE GEOLOGIA, 33., Rio de Janeiro, 1984. Anais. Rio de Janeiro, SBG. p.1794-1808.

ALMEIDA, F.F.M. (1958) O Planalto Paulistano. In: A cidade de São Paulo, estudos de geografia urbana: brasiliana. São Paulo, Nacional. v. $14, \mathrm{t} .1$, p.113-167.

ALMEIDA, F.F.M. (1964) Fundamentos geológicos do relevo paulista. Boletim Instituto Geográfico e Geológico, n.41, p.169-263.

CARVALHO, A.M.V.; LEINZ, V. (1957) Contribuição à geologia da Bacia de São Paulo. Boletim Faculdade de Filosofia Ciências e Letras. Geologia. USP, n.205, p.15-61.

COPPEDÊ, A.J. (1988) Formas de relevo e perfis de intemperismo no leste paulista: aplicaçōes no planejamento de obras civis. São Paulo, 152p. (Dissertação - Mestrado) Escola Politécnica, Universidade de São Paulo.

COUTINHO, J.M.V. (1989) Alguns aspectos sedimentológicos e tectônicos na área da Bacia de São Paulo. In: WORKSHOP "GEOLOGIA DA BACIA DE SÃO PAULO", 1989. Coletânea de comunicações. São Paulo, SBG-IG/USP. p.12-15.

MELO, M.S.; RICCOMINI, C.; HASUI, Y.; ALMEIDA, F.F.M.; COIMBRA, A.M. (1985) Geologia e evolução do sistema de bacias tafrogênicas continentais do sudeste do Brasil. Revista Brasileira de Geociências, v.15, p.193-201.

METROPOLITANA DE SÃO PAULO (1990) Dados do relatório do Metrô: relatórios de sondagens. 96p. (inédito).

SUGUIO, K. (1980) Sintese dos conhe- 
cimentos sobre a sedimentação da Bacia de São Paulo. In: MESA REDONDA ASPECTOS GEOLÓGICOS E GEOTÉCNICOS DA BACIA SEDIMENTAR DE SÃO PAULO, São Paulo, 1982. Publicação Especial. São Paulo, ABGE/SBG. p.2532.

SUGUIO, K.; BARBOUR, A.P. (1969) Morfologia das estruturas limoníticas da Bacia de São Paulo. Anais da Academia Brasileira de Ciências, v. 41, n.2, p.161-180.

SUGUIO, K.; COIMBRA, A.M.; CATTO, A.J. (1972) Estudo comparativo dos sedimentos e rochas cristalinas circundantes da Bacia de São Paulo (granulometria e minerais pesados). In: CONGRESSO BRASILEIRO DE GEOLOGIA, 26., Belém, Anais. v.1, p.141-153.

SUGUIO, K.; FÚlFARO, V.J.; COUTINHO, J.M.V. (1971) Tipos de contatos e estruturas sedimentares associadas da Bacia de São Pulo. In: CONGRESSO BRASILEIRO DE GEOLOGIA, 25., São Paulo, 1971. Anais. v.2, p.215-218.

TAKIYA, H. (1991) Aplicação de métodos quantitativos espaciais a dados geológicos da Bacia de São Paulo. São Paulo, 109p. (Dissertação - Mestrado) - Instituto de Geociências, Universidade de São Paulo.

J.B.Sígolo - Instituto de Geociências, Universidade de São Paulo, Caixa Postal 11.348, CEP 05422-970, São Paulo, SP, Brasil. 